\title{
When the going gets tough ...
}

\author{
Britain's epidemic of foot-and-mouth disease gave the government's chief \\ scientific adviser, David King, a baptism of fire. He has emerged with his \\ political standing enhanced, says David Adam.
}

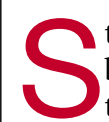
tarting any new job can be difficult, but spare a thought for David King, the British government's chief scientific adviser. Barely settled in behind his desk, King was thrown headlong in March into a crisis that threatened the future of British farming. Foot-and-mouth disease was spreading like wildfire, and epidemiologists were warning of a catastrophic "meltdown".

King seized the initiative. He surrounded himself with experts, including leading epidemiological modellers. This group's conclusions fed straight into government policy, through King's meetings with Prime Minister Tony Blair, held three or four times a week. In effect, King had wrested control from the Ministry of Agriculture, Fisheries and Food (MAFF). Almost daily, he faced the media to defend the government's handling of the crisis. "I was completely taken over by foot-and-mouth disease and my diary just had to be swept aside," he says.

For a British chief scientific adviser to have such a direct and obvious influence over government policy is unusual - King's predecessor, Robert May, never found himself on national television night after night. "Most politicians at least know who David King is now," says an official with one of the government-funded research councils. "Some didn't know who Bob May was even after he'd been there for five years."

For many, the pressure of becoming a pivotal figure in a national emergency would be hard to bear. But now the epidemic has tailed off sufficiently for King to grant an indepth interview, it is clear that he thrived on the challenge. And he seems determined to use his raised political profile to maximum effect. King has already won a review of public spending on research, and now aims to improve the effectiveness of scientific advice across government.

There is "no question", King says, that the epidemic helped him to find his feet. More importantly, he thinks it showed politicians the value of scientific advice. "It has been enormously powerful in bringing to the attention of the prime minister how science can advise policy-making and be effective."

King came to his present role from Cambridge University, where he headed the chemistry department. He was born in South Africa in 1939 and graduated in chemistry from Witwatersrand University in
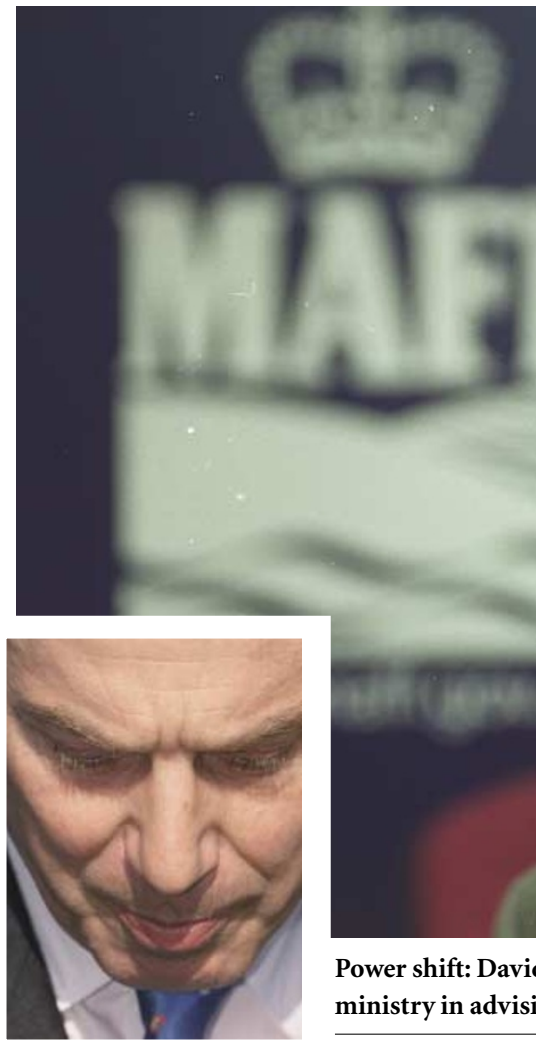

Johannesburg, where he completed a $\mathrm{PhD}$ before moving to London's Imperial College in 1963. Spells at the universities of East Anglia and Liverpool followed, before King arrived in Cambridge in 1988. He has an international reputation for his work on surface chemistry and catalysis, and still carries out research in Cambridge for one day each week, supervising more than a dozen postgraduate students.

\section{Key players}

Officially appointed in October last year, King says he only completed the transfer from academic life at the end of December. In the weeks that followed, he concentrated on building his relationships with the key players on Britain's science policy scene. Then foot-and-mouth took over.

Reflecting on the handling of the epidemic, King says his only regret is his initial reluctance to get directly involved. "My first reaction was that this was something that wasn't going to go away quickly - foot-andmouth never does," he says. "But I did feel that I would not interfere with MAFF and I would leave them to run the campaign."

That changed on 21 March, when King attended a meeting with John Krebs, head of the Food Standards Agency, and four research groups that were using computer models to predict the spread of the disease (see Nature 411,977;2001). The epidemiologists all delivered the same, bleak message: foot-and-mouth was running out of control, and a more rigorous culling policy was needed to rescue the situation. "It became apparent that modelling was required," says King. "Then once you've got the models going you could set up different control scenarios and see what was needed."

King set the modellers to work. Within two days, he presented Blair with what became known as the '24-/48-hour' policyto kill infected animals within 24 hours and those on surrounding farms within 48 . King says that all four modelling groups predicted that such drastic measures were required. "So I felt fairly confident and stuck my neck out."

King makes no attempt to disguise his blurring of the line between advising on policy and making it. "When I presented my 
policy decision to the prime minister there was a very short timescale," he explains. At that time the number of cases was doubling every nine days. "So the first thing I said was 'act fast," King continues. "We had calculated a whole range of scenarios but I simply said that this is the one that will work. So it wasn't a matter of giving what I thought would be a confusing set of options."

King is clearly comfortable with taking responsibility for the policy that was adopted. But as the cull passed 3 million, and images of mass graves and pyres dominated the media, criticism mounted, with farmers and some veterinary scientists questioning the need to kill so many animals (see Correspondence, page 477). Some critics in the media even suggested that the policy was designed to bring the epidemic under control before 7 June, the date of the general election, already delayed from 3 May by the epidemic.

King dismisses this idea, and plays down the significance of the disagreements between veterinary scientists and epidemiologists - both represented on his expert group. "It's certainly true that there has been a creative tension throughout, but I wouldn't say that there's been an argument between the vets on one hand and the epidemiologists on the other," he says.

King is adamant that the culling was justified. Some of the critics, he argues, do not understand the sophistication of the models that his group employed, and the fact that they were crunching 'real' data. "The outbreak had been going almost a month and by using the way it was developing you could tell what the incubation time and the infectious period was, and add that to the data to predict how it would go." King claims that had he not intervened, the eventual size of the cull needed to stamp out the disease could have been far worse. "We were predicting that we could lose half the farm animals in the UK."

Even with rigorous culling, the models predicted a long 'tail' of infections that is still occurring. King's main current worry is that complacency will set in, causing a relaxation in the 'biosecurity' measures introduced to prevent the disease's spread. If the outbreak

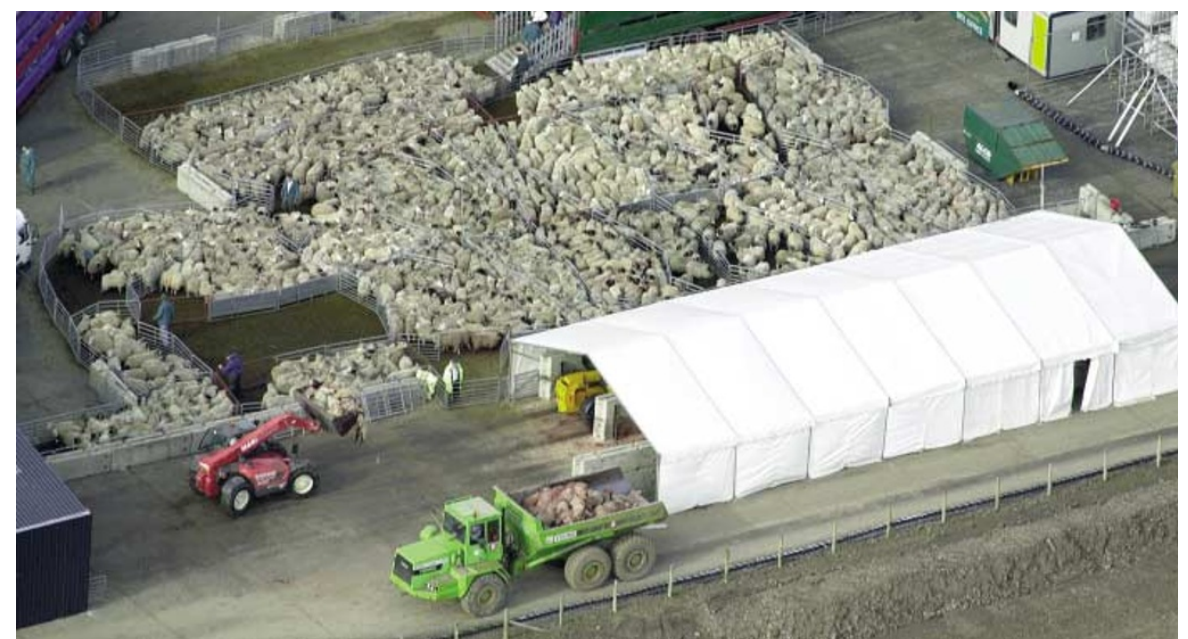

Killing fields: sheep waiting to be culled in Cumbria at the height of the foot-and-mouth outbreak.

survives the summer, he warns, it could flare up again, under the cooler conditions that favour the virus's transmission.

MAFF, meanwhile, did not survive the summer, being replaced after Blair's election victory with DEFRA, the Department for Environment, Food and Rural Affairs (see Nature 411, 727; 2001). Many observers feel that the defunct ministry failed to learn from previous mistakes. "The first lesson from the foot-and-mouth epidemic is the same lesson we learnt from BSE," says King. "That is: when there's a crisis you must bring on board as quickly as possible the widest range of scientific advice." Which MAFF failed to do? "Which I did," he says, with a relaxed smile.

\section{What Tony wants}

King, who claims to have received only a few hours of media training, certainly has the poise of his new political colleagues. At least at present, he also has regular access to the prime minister — which is of huge significance in a government said by insiders to be dominated by two words: "Tony wants ..."

How King uses this influence will be crucial. Already, he has ensured that science will be included in the next cross-departmental review of government spending, due to be completed by summer 2002. Two previous reviews, carried out since the Labour govern-

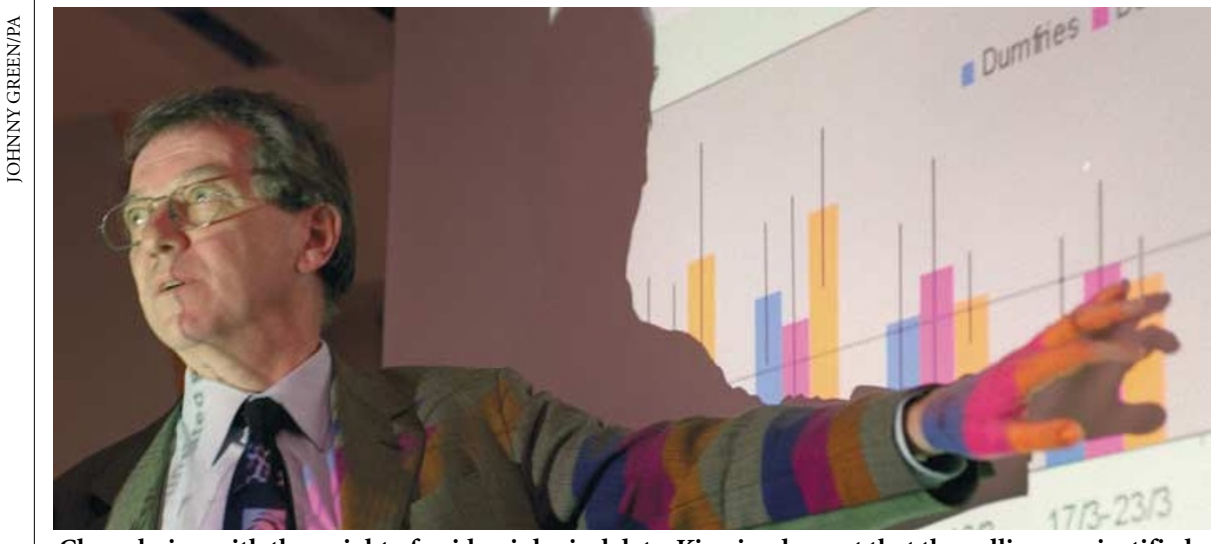

Clear choice: with the weight of epidemiological data, King is adamant that the culling was justified. ment came to power in 1997, resulted in increased spending on research.

King's next priority is to improve the standard of scientific advice across the whole of government. On this point, he is not afraid to criticize his political paymasters, arguing that the decision to shed much of the government's in-house scientific expertise has caused problems. Although this policy was instituted by the previous Conservative government, Blair's administration has continued the trend, most recently spinning off three-quarters of the Defence Evaluation and Research Agency into a company called QinetiQ (see Nature, 412, 9; 2001).

"The net result is that we've lost a fair amount of the science base from within the civil service, so we don't have these people bubbling up into top positions," says King. "The problem with an organization that outsources all of its resources is that, if it does it too rigorously, it no longer knows even what questions to ask."

To plug these gaps, King wants to bring into government top scientists from universities and industry, starting at the successor to the ill-fated MAFF. "I expect that DEFRA will shortly be advertising for a chief scientific adviser along exactly these lines," he says. "They will parachute in an expert on environment and agriculture."

King admits that he is still getting used to his job, saying there is a "massive culture gap" between life as a university professor and as a civil servant. Maybe so, but King shows every sign of becoming an effective civil servant who is also a consummate politician. If that means that science assumes a central role in government thinking, he is likely to be a popular figure among British researchers.

"My belief, and the prime minister agrees with this, is that science today deals with exceptionally complex phenomena but can maintain a quantitative understanding," says King. "That was one of the lessons of this outbreak, that you can take a complex phenom enon and can really say something useful." David Adam is a news and features writer for Nature. 